\title{
Experimental and Numerical Investigation of the Cryogenic Hydrogen Storage Processes over MOF-5
}

\author{
Xu Xian Hou a, ${ }^{\text {, }}$, Martin Sulic ${ }^{b}$, Jerome P. Ortmann ${ }^{c}$, Mei Cai ${ }^{c}$, Amlan Chakraborty ${ }^{d}$ \\ a Optimal CAE Inc., Plymouth, MI 48170, USA; peter.hou@gm.com \\ ${ }^{b}$ currently at: Savannah River National Laboratory, Aiken, SC, 29808; martin.sulic@gmail.com \\ ${ }^{\mathrm{C}}$ Chemical and Materials Systems Laboratory, General Motors R\&D Technical Center, Warren, \\ MI 48090, USA; jerome.p.ortmann@gm.com; mei.cai@gm.com \\ ${ }^{d}$ currently at: Veeco - MOCVD Operation, Somerset, NJ 08873; amlanchak@gmail.com \\ *Corresponding author. Tel.: 15862654016
}

\section{Highlights}

- A cryogenic $\mathrm{H}_{2}$ storage system was built with a 3-liter tank and MOF-5.

- Flow-through cooling technique was tested and evaluated.

- Electric heating was used and studied for discharging.

- Charging and discharging processes were simulated with 3D model.

- Cyclic charging process was tested and found to be very effective.

\begin{abstract}
The processes of hydrogen charging to and discharging from a 3-liter cryogenic tank have been studied experimentally and numerically. This study investigated the impacts of factors such as mass flow rate, outlet opening time, bed density, and heating power on the hydrogen charging and discharging processes. For charging, it was found that the flow-through cooling technique could remove the adsorption heat in the process, but some issues such as channeling phenomenon and large thermal mass of the system need to be addressed. Low initial bed temperature is beneficial for hydrogen storage in terms of the efficiency of charging operation. When the bed density of metal organic framework-5 (MOF-5) is increased from $164 \mathrm{~kg} / \mathrm{m}^{3}$ to $174 \mathrm{~kg} / \mathrm{m}^{3}$, the total storage of hydrogen within the tank increases accordingly. It is found that pressure is the major factor that determines the storage of hydrogen, which increases significantly with the pressure within the tank. For discharging, high pressure in the storage tank can
\end{abstract}


be used to release hydrogen for a certain period of time without heating. However, in order to maintain the desired hydrogen discharge rate, a heat source is eventually needed. This heat must be supplied in order to desorb the additional hydrogen from the system. To deal with the channeling phenomenon in the charging process, cyclic charging was tested and adopted.

Keywords Adsorption · MOF-5 - Dubinin-Astakhov · Cryogenic-adsorption · Hydrogen storage

\section{INTRODUCTION}

The commercial success of hydrogen fuel cell powered light-duty vehicles depends on their driving range being comparable to that of gasoline and diesel engines. The on-board application of hydrogen as an energy source requires the storage of hydrogen to be sufficient and easy to use [1-2]. Physical adsorption is considered to be a feasible and competitive method for hydrogen storage [3-5]. The motivation to explore hydrogen storage at cryogenic temperature and high pressure is warranted since the two factors have a significant effect on hydrogen storage $[2,6]$.

Successful adsorbent materials are required have large surface areas [7-12]. MOFs offer good gravimetric capacity as adsorbents, as well as fast and reversible kinetics [13]. In comparison to other candidates, MOF-5 has a significantly higher total hydrogen desorption efficiency, and a lower heat requirement for systems of 60 and 200 bar [14-15]. It has been found to be an attractive adsorbent in cryogenic hydrogen storage systems [16].

The operations studied in this paper are mainly charging and discharging of cryogenic hydrogen, although dormancy and venting have also been discussed previously [17-18]. According to the standards set by DOE, the ultimate gravimetric deliverable hydrogen storage is $7.5 \%$ of the mass of the storage system, and the hydrogen must be filled into the system within three minutes [2]. To meet those targets, the system must be capable of both storing enough hydrogen quickly during charging and retaining as little hydrogen as possible at the end of discharging. 
For charging, adsorption heat produced during the process must be removed quickly in order to store enough hydrogen within required time period [19-20]. For discharging, the outlet mass flow rate of hydrogen must meet the vehicle's power requirements. The mass flow rate requested by a light duty car is usually about $2 \mathrm{~g} / \mathrm{s}$ for a full size fuel cell [22]. To keep adequate pressure in the storage tank, heat must be supplied to the bed to compensate for the desorption heat. Since MOF-5 is a poor heat conductor, heating the adsorption bed evenly during discharging presents a challenge [23]. The amount of hydrogen remaining in the storage tank at the end of discharging is a function of temperature and pressure.

Both experimental and modeling methods have been used to study cryogenic hydrogen storage systems with various storage tank designs. Analyses of the effects of operating parameters such as mass flow rate and temperature have been conducted [17-20, 24-26]. The early efforts on physical hydrogen adsorption focused on using activated carbon as the adsorbent, and operating temperatures could be around $290 \mathrm{~K}$ with pressures under 20 bar [19-20]. A lumped-parameter model for a cryogenic hydrogen storage tank with MOF-5 pellets as the adsorbent was proposed by Kumar et al. [17, 18], which raised the importance of energy management. For desorption, Kumar et al. [17] and Michl et al. [24] studied recirculating hot hydrogen through the bed to enhance hydrogen desorption. Xiao et al. [20, 25-26] simulated a whole chargedischarge cycle of hydrogen storage adsorption on activated carbon both at room temperature and cryogenic temperature, realizing the importance of heat conductivity within the adsorbent bed. Hardy et al. [27] studied the charging process for a cryogenic hydrogen storage system with activated carbon and MOF- 5 as adsorbents, finding that pressure work was vital for the balance of energy in the charging process. Chakraborty et al. [22] presented a 3D discharge model to simulate extraction of hydrogen from a full-sized storage bed filled with either activated carbon or MOF-5. The heat supply requirement was met by a heating element that included a helical coil and a central longitudinal rod. Ubaid et al. [38] numerically investigated the effect of flow-through cooling heat removal on the storage and thermal performances of a $20 \mathrm{~m}^{3} \mathrm{MOF}-5$ cryogenic hydrogen reservoir. The model was validated by the experimental data from a $2.5 \mathrm{~L}$ storage tank filled with MOF-5. 
Various isotherms have been used to describe the adsorption and desorption processes in the system, including Langmuir [17, 28], Unilan [23] and Dubinin-Astakhov (DA) [29] models. The DA isotherm is a modified version of the Dubinin-Radushkevitch model [29], which assumes that the adsorption of a species over a microporous material is a volume-filling process [6]. In the DA model, free energy of adsorption, $E_{a}$, was modified to account for enthalpic and entropic contributions as follows,

$$
E_{a}=\alpha+\beta T
$$

The model provides a significantly superior fit for hydrogen and nitrogen when it is considered temperature independent [6, 27, 30-35].

MOF-5 powder has been used as the adsorbent in this work. The flow-through cooling technique has been applied for charging. In this paper, the final temperature and pressure during charging are $80 \mathrm{~K}$ and 60 bar [21]. Electric heating has been applied for discharging. The final temperature and pressure after discharging are $150 \mathrm{~K}$ and 4 bar based on the consideration of hydrogen adsorption profile and storage tank design [2]. A comprehensive 3-D COMSOL $®$ Multiphysics model was built to simulate the charging and discharging processes, with consideration for the effects of convection and pressure work. The DA model has been adopted as the adsorption isotherm. The following contributions are made to the study of cryogenic adsorbent hydrogen storage systems: (1) A cryogenic hydrogen storage system with a 3-liter stainless steel storage tank has been installed in a vacuum chamber. (2) The flow-through cooling technique has been tested for the charging process. (3) An electric heating element has been designed to provide evenly distributed heating for discharging and the effects of various factors on temperature profiles and the amount of discharged hydrogen have been investigated. (4) Cyclic cooling method has been tested.

\section{EXPERIMENTAL}

\subsection{Setup}

A custom cryogenic apparatus was built for pilot-scale testing of the flow-through cooling technique and the analysis of hydrogen discharging from an adsorbent (setup is shown in Figure 1 in brief). Ultra-high purity grade hydrogen was provided by Airgas Inc. Liquid nitrogen provided by Praxair® was used to cool down the pressurized inlet 
hydrogen. The storage tank was positioned horizontally in a vacuum chamber. The vacuum was maintained by an automatically controlled vacuum pump. Under the cover of the vacuum chamber, another liquid nitrogen cooled heat exchanger was used to control the temperature. The mass flow rate of hydrogen was monitored by a mass flow control manifold, composed of selectable subsonic orifice valves and meters. Both inlet and outlet mass flow control devices are provided by Engineering Innovation, Inc. Both inlet and outlet mass flow rates have been calibrated with a $0.15 \mathrm{~m}^{3}$ transparent container, based on the ideal gas low around room temperature and atmospheric pressure.

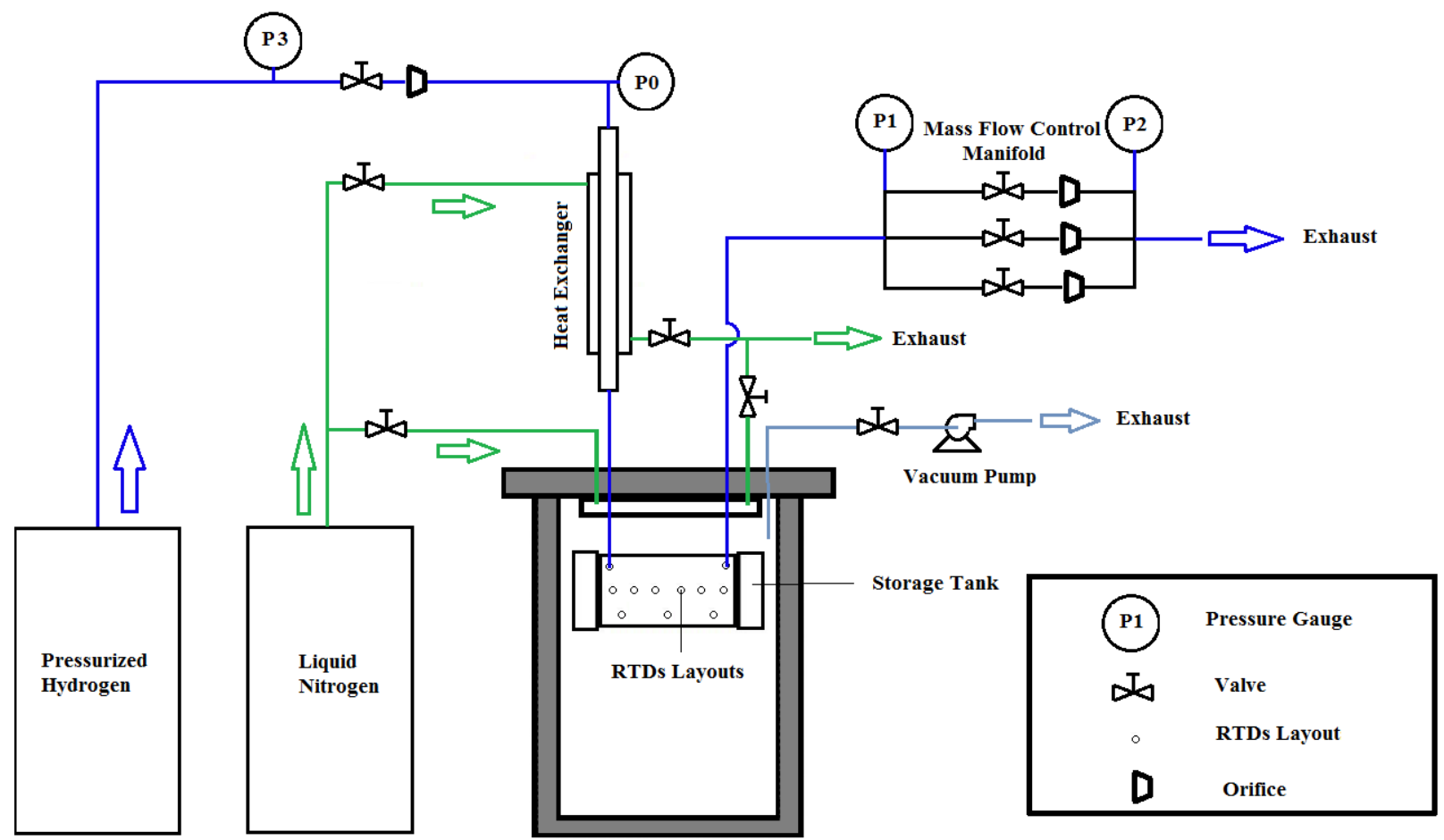

(a) 


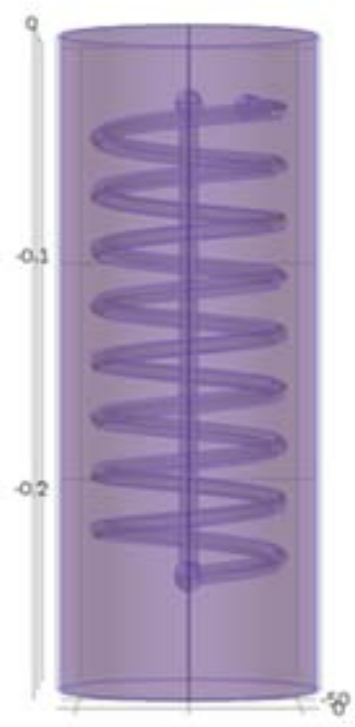

(b)

Figure 1 Schematic of (a) experiment setup; and (b) model setup

\subsection{Cryogenic 3-liter storage tank and adsorbent}

The cryogenic storage tank is a 3-liter cylindrical container, with the sample bed having a length of $0.292 \mathrm{~m}$ and a diameter of $0.114 \mathrm{~m}$. It was sealed in a chamber that was evacuated in order to establish adiabatic conditions and the environment was controlled at cryogenic temperatures. MOF- 5 powder provided by BASF was used as the adsorbent. After being sealed within the storage tank the adsorbent was activated under vacuum and heated for several days. Approximately $526 \mathrm{~g}$ of pure MOF-5 powder was packed into the storage tank initially, resulting in an adsorbent bed density of 0.164 $\mathrm{g} / \mathrm{cm}^{3}$. The tank was fitted with a metal filter disk ( $2 \mu \mathrm{m}$ pore size) at each end of the bed to prevent movement of the powder while maintaining maximum flow of hydrogen. The upstream filter acts as a diffuser for the inlet gas and aids in evenly distributing the flow through the front of the bed. A helical coil resistive heater was installed within the adsorbent bed. Twenty two high precision resistive temperatures devices (RTDs) were used to measure temperatures in the bed and at the inlet and outlet ports. The positions of the RTDs are shown in Figure 2. The fractions within the circles are the ratios of internal radius of the tank over the distances of the RTD ends from the center of the tank. 


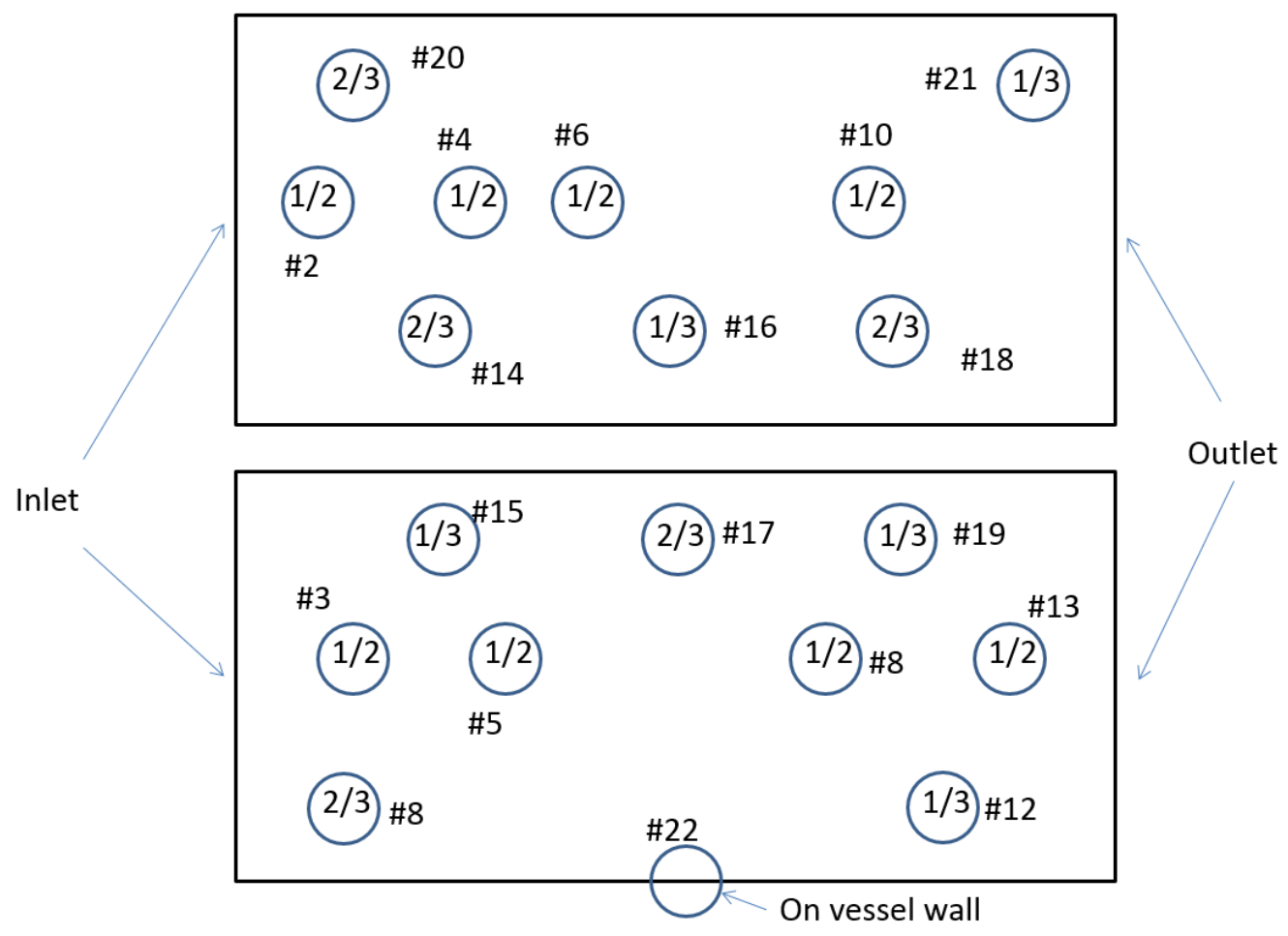

Figure 2 The positions of RTDs. The fractions within the circles are the ratios of internal radius of the tank over the distances of the RTD ends from the center of the tank.

\subsection{Procedures}

The charging and discharging experiments have been done separately. Each test has been done at least twice to check the repeatability. Prior to all charging experiments, the starting conditions (e.g. $150 \mathrm{~K}$ and 4 bar) were established for the storage tank by flowing hydrogen through the tank at 4 bar. With the system stabilized at $150 \mathrm{~K}$ and $4 \mathrm{bar}$, charging proceeded according to the designed plan.

Prior to all discharging experiments, the initial conditions of $80 \mathrm{~K}$ and 60 bar were established in the system. With the stabilized system, the inlet was sealed and the outlet was opened to discharge. The outlet flow rate was controlled by the instrumentation software. A helical coil heater with controllable heat flux was used to aid in hydrogen desorption. The pressure and temperature measurements within the storage tank were collected. When the internal pressure was 4 bar, the outlet was then sealed and the temperature in the system was allowed to reach equilibrium. The final 
pressure and temperature measurements were then recorded in order to precisely determine the mass of hydrogen remaining in the MOF- 5 bed.

\section{MODELING}

The objective of the model development was to simulate the charging and discharging experiments, predicting the transient temperature profiles of the processes. The model was based on the work done by Hardy et al. [27] and Chakraborty et al. [22], with additions made to represent unique attributes of our cryogenic MOF-5 hydrogen storage system. In particular, a helical coil heater with a central rod was included in the model. While it provides heat to the system to compensate for desorption heat, it also affects the gas flow.

\subsection{Adsorption isotherms}

Similar to the work done previously by other researchers [20, 22, 25-27], the modified DA model was adopted in this work $[6,30]$. The absolute adsorption, $\mathrm{n}_{\mathrm{a}}$, in the modified DA model can be expressed as [6],

$$
n_{a}=n_{\max } \exp \left[-\left(\frac{R T}{E_{a}}\right)^{2} \ln ^{2}\left(\frac{P_{D A}}{P}\right)\right]
$$

The total moles of hydrogen per mass of adsorbent, $n_{\text {total, }}$ can be obtained with

$$
n_{\text {total }}=n_{a}+\rho_{g}\left(V_{V}-V_{a}\right)
$$

The differential energy of adsorption regarding absolute adsorption, $\mathrm{n}_{\mathrm{a}}$, has been previously reported $[6,30]$,

$$
\begin{aligned}
\Delta \bar{U}_{a} & =\left[\frac{\partial \Delta U_{a}}{\partial n_{a}}\right]_{T, V}=R T-\alpha \sqrt{-\ln \left(\frac{n_{a}}{n_{\max }}\right)} \\
\Delta U_{a} & =U_{a}-n_{a} u_{g}^{0} \\
U_{a} & =U_{c}-u_{s}
\end{aligned}
$$

\subsection{Mass conservation equation}

The mass conservation equation in porous media can be expressed as [36]: 


$$
\begin{aligned}
& \frac{\partial\left(\varepsilon_{b} \rho_{g}\right)}{\partial t}+\nabla\left(\rho_{g} \vec{v}\right)=-\left(1-\varepsilon_{b}\right) \rho_{b} M_{H_{2}} \frac{\partial n_{a}}{\partial t} \\
& \vec{v}=\varepsilon_{b} \vec{u} \\
& \varepsilon_{b}=\rho_{b}\left(V_{V}-V_{a}\right)
\end{aligned}
$$

The right side of equation (7) is the mass source term, which results from the adsorption/desorption process.

\subsection{Momentum conservation equation}

Darcy's law was implemented to describe the pressure variation in the bed and the equation can be written as [36]:

$$
\begin{aligned}
& \nabla P=-\alpha_{b} \mu_{g} \vec{v} \\
& \alpha_{b}=\frac{150\left(1-\varepsilon_{b}\right)^{2}}{\varepsilon_{b}^{3} D_{p}^{2}}
\end{aligned}
$$

\subsection{Energy conservation equation}

The components considered for the heat transfer process in the system include heat transfer in the porous media, heat flux from the heating elements, and heat transfer in the solid phase such as the vessel wall and heating elements. For heat transfer in the porous media, the energy conservation equation is [36],

$$
\begin{aligned}
& \left(\rho C_{p}\right)_{e q} \frac{\partial T}{\partial t}+\rho C_{p} \vec{v} \cdot \nabla T=\nabla \cdot\left(k_{e q} \nabla T\right)+Q \\
& \left(\rho C_{p}\right)_{e q}=\Theta_{p} \rho_{p} C_{p, p}+\Theta_{f} \rho C_{p} \\
& k_{e q}=\Theta_{p} k_{p}+\Theta_{f} k \\
& \Theta_{p}+\Theta_{f}=1
\end{aligned}
$$

Where $\left(\rho C_{p}\right)_{\text {eq }}$ is the equivalent volumetric heat capacity at constant pressure. The heat source, $Q$, includes adsorption heat source, sorption energy, and pressure work [22, 27].

$$
Q=-\left(\frac{S_{0}}{M_{H_{2}}}\right) \Delta H-\rho_{b}\left(\frac{\partial \Delta U_{a}}{\partial t}+\frac{\partial\left(u_{g}^{0} n_{a}\right)}{\partial t}\right)-\frac{T}{c} \frac{\partial c}{\partial T}\left(\varepsilon_{b} \frac{\partial P}{\partial t}+\vec{v} \cdot \nabla P\right)
$$

The heat transfer between the wall and heating elements can be expressed as [22, 36], 


$$
\rho_{m} C_{p m} \frac{\partial T}{\partial t}-\nabla \cdot\left(k_{m} \nabla T\right)=0
$$

\subsection{Material properties and equation parameters}

For hydrogen at cryogenic conditions, the properties are functions of temperature $(K)$ and pressure $(\mathrm{Pa})$. The compressibility factor $Z(T, P)$, molar enthalpy $h(T, P)$, heat conductivity $k(T, P)$, and viscosity $\mu(T, P)$, were obtained from the NIST data base [37]. The regression coefficients used by Hardy et al. [27] and Chakraborty et al. [22] to describe the change of those properties with temperature and pressure was adopted. The parameters for the DA equations and model design are listed in Table 1.

Table 1 - Parameters for the modified Dubinin-Astakhov equations [27] and MOF-5 bed geometry and properties

\begin{tabular}{|l|r|}
\hline \multicolumn{1}{|c|}{ DA Equation Parameters } & \multicolumn{2}{c|}{ Value } \\
\hline $\mathrm{n}_{\max }\left(\mathrm{mol} / \mathrm{kg} \_\right.$ads $)$ & 38.1 \\
\hline $\mathrm{P}_{\mathrm{DA}}(\mathrm{MPa})$ & 2403 \\
\hline$\alpha(\mathrm{J} / \mathrm{mol})$ & 11.5 \\
\hline$\beta(\mathrm{J} / \mathrm{mol} \cdot \mathrm{K})$ & 0.00194 \\
\hline $\mathrm{V}_{\mathrm{a}}\left(\mathrm{m}^{3} / \mathrm{kg}\right.$ _ads $)$ & 0.0062 \\
\hline $\mathrm{V}_{\mathrm{V}}\left(\mathrm{m}^{3} / \mathrm{kg}\right.$ _ads $)$ & Value \\
\hline MOF-5 bed geometry and properties & 0.1034 \\
\hline Bed diameter $(\mathrm{m})$ & 0.2921 \\
\hline Bed height $(\mathrm{m})$ & 164 \\
\hline MOF-5 bulk density $\left(\mathrm{kg} / \mathrm{m}^{3}\right)$ & 8.38 \\
\hline Number of helical heating coil turns & 0.08 \\
\hline Major diameter of helix $(\mathrm{m})$ & 0.008 \\
\hline Minor diameter of helix $(\mathrm{m})$ & 0.05 \\
\hline Axial pitch $(\mathrm{m})$ & \\
\hline
\end{tabular}

\subsection{Model assumptions, initial and boundary conditions}


A 3-D model is applied for the processes. The model assumes that the powder is distributed homogeneously within the tank. For simplification, only MOF-5 bed and the surrounding storage tank wall were included in the model. As the outside surface of the storage tank is surrounded by vacuum in the experiment, the tank is assumed to be insulated perfectly in the model. The heating element is approximated by a rod and eight circular tube and the ends of the helical coil and rod merge with spheres to eliminate the sharp edges on those ends. Due to the symmetry of the modeling domain, a quarter of the system is simulated in the model.

\subsubsection{Charging}

In the simulation of the charging process, the actual initial pressure for the model is obtained from the experiment. The initial temperature in the tank can be varied from $80 \mathrm{~K}$ to $120 \mathrm{~K}$, depending on the case studied. The temperature and pressure of the inlet hydrogen from the experiment can be used as the boundary conditions in the model.

\subsubsection{Discharging}

In the simulations of the discharging process, the flow at the open end of the bed is assumed to be plug flow. The initial temperatures for the bed, wall, and heating element are all $80 \mathrm{~K}$ and the initial pressure within the bed is 60 bar. Heat flux towards the bulk of the bed from the helical coil and longitudinal rod is constant, and adiabatic conditions are set at the outside wall of the storage tank.

\subsection{Software}

COMSOL $®$ Multiphysics v4.2 finite element software was applied. As MOF-5 is used as adsorbent, the flow of hydrogen in the system is a flow thorough a porous media. The modules used are free and Porous Media Flow (FP) and Heat Transfer in Porous Media (HT). For the discharging simulations, the flow rate of hydrogen is slow compared to that of charging. The modules used in the discharging simulations are Darcy's Law (DL) and Heat Transfer in Porous Media (HT).

\section{RESULTS AND DISCUSSION}




\subsection{Charging process}

For the charging process, the main task is to fill a large amount of gaseous hydrogen into the storage tank within a limited time. This process is constrained by the maximum allowable operating pressure for the system and the practical volumetric flow rate. The adsorption heat must be removed in a timely manner. The flow-through cooling technique was adopted for this purpose, specifically through flowing an additional amount of cold hydrogen through the tank. For all of the experiments the evolutions of temperature, pressure, and hydrogen storage in the process are monitored. Several factors, including MOF-5 bed density, initial bed temperature, outlet mass flow rate, and outlet opening time have been investigated. For the simulations, the parameters of inlet hydrogen, such as temperature, pressure, and mass flow rates were treated as known values in the model. The profiles of bed temperature and hydrogen storage parameters, including absolute adsorption, $n_{a}$, and total hydrogen storage, $n_{\text {total }}$, are predicted and compared with the experimental results. In order to make the comparison relevant, it is essential that the pressure profiles and the inlet and outlet mass flow rates in the model be the same as those in the experiment.

\subsubsection{Temperature and hydrogen storage distribution in the charging process}

A brief description of the temperature and hydrogen storage distribution patterns in the charging process can be beneficial to our understanding of the process. The plots of these distributions have been published elsewhere and are omitted here for the sake of brevity [39]. The simulation data indicate that the region of the bed near the inlet has the lowest temperatures due to the cooling effect of incoming hydrogen. Temperatures in regions downstream increase due to the adsorption heat. The hottest region is that near the center line of the bed, due to the inhomogeneity of the flow. The hydrogen storage in different regions of the tank is highly dependent on the distribution of the temperature. Because the pressure variation in the bed is minor, the hydrogen storage distribution in a region is mainly determined by the region's temperature [40].

\subsubsection{Effect of MOF-5 bed density in the charging process}


To investigate the effect of adsorbent density on adsorption, two levels of adsorbent densities have been studied. The weight of MOF- 5 in the system was increased from $0.526 \mathrm{~kg}$ to $0.557 \mathrm{~kg}$, which changed the bed density from $164 \mathrm{~kg} / \mathrm{m}^{3}$ to $174 \mathrm{~kg} / \mathrm{m}^{3}$. The initial temperatures were approximately $81 \mathrm{~K}$, and pressure was ramped from 5 to 60 bar within $75 \mathrm{~s}$ while the outlet was closed. After $75 \mathrm{~s}$, the outlet was opened and flow-through cooling lasted for $225 \mathrm{~s}$. The inlet temperature of hydrogen was maintained at about $82 \mathrm{~K}$. Both inlet and outlet mass flow rates were monitored. The inlet mass flow rate was maintained at $0.5 \mathrm{~g} / \mathrm{s}$. The pressure within the tank was kept constant at 60 bar the entire time during the flow-through cooling process. With those conditions, the outlet flow rate was smaller than, but close to, the inlet flow rate. As the system cooled down, less and less hydrogen was stored in the tank. Ideally, as the temperature within the tank approached that of inlet hydrogen, ignoring the effect of pressure work, the inlet and outlet mass flow rates will be very close.

In the simulation, the mass flow rates for the inlet and outlet in the experiment are used as input for the calculation. The experimental data and simulation results on bed temperature and hydrogen storage are shown in Figure 3(a) and 3(b). The average bed temperature in the experiment was obtained by averaging the measurements of the RTDs, while that of the model was obtained by averaging the value of the entire domain of the adsorption bed. The data indicates that as the adsorbent density increases, average bed temperature decreases. The average temperature of the bed increased dramatically in the first 50 seconds. The bed started to cool slowly after $75 \mathrm{~s}$ when flowthrough cooling mode was active. At the end of charging, the average bed temperature was higher than $80 \mathrm{~K}$. The effect of adsorbent density on the final average temperature is minor. In Figure $3(b)$, the data indicate that total hydrogen storage increases with the total weight of adsorbent. 


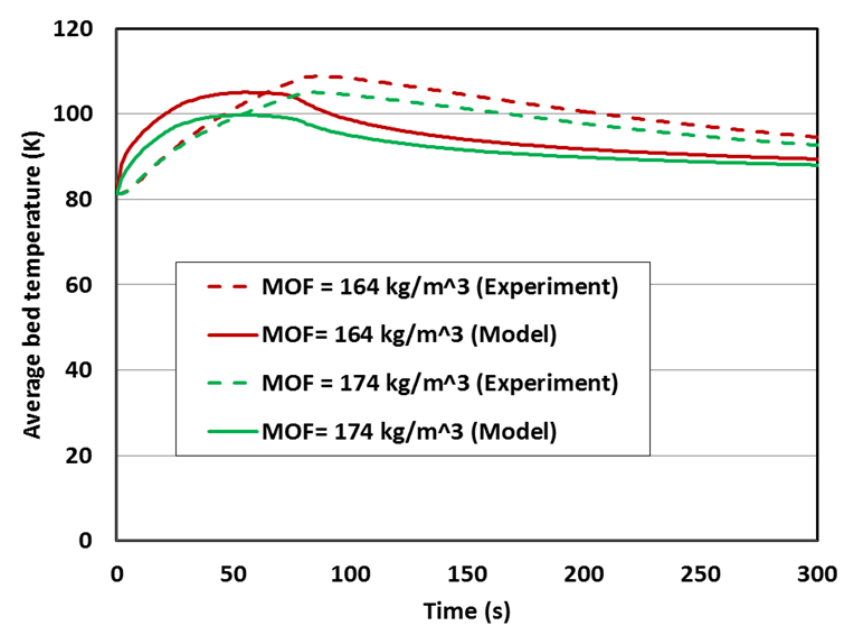

(a)

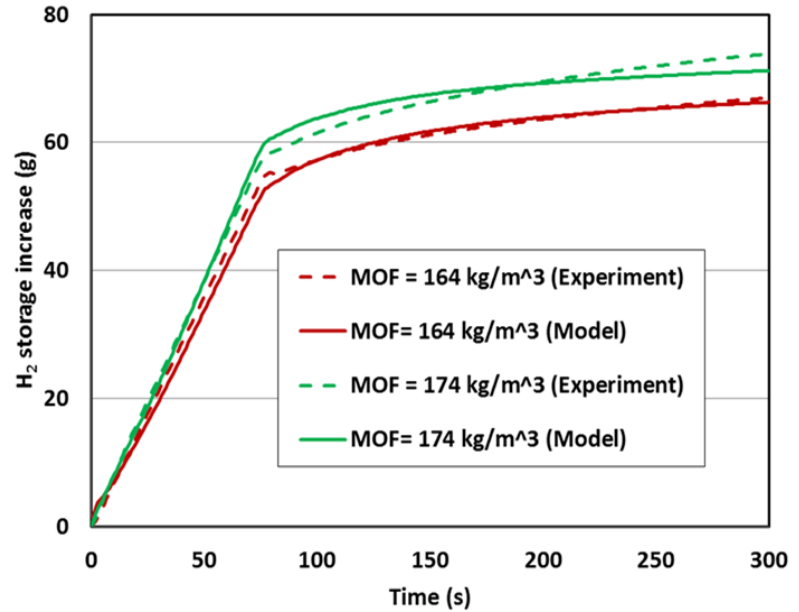

(b)

Figure 3. (a) Effect of MOF-5 bed density on average bed temperature in the charging process; (b) Hydrogen storage increase as a function of MOF-5 bed density in the charging process.

\subsubsection{Effect of outlet opening time in the charging process}

When hydrogen is introduced into the storage tank, temperatures in the vessel tend to increase due to adsorption heat, sorption energy, and pressure work. The effect of outlet opening time on the outcome of the charging process is twofold. Opening the outlet earlier may help remove the heat within the tank earlier. However, opening the outlet too early may affect the pressure build up in the vessel. Therefore, it is of value to study the effect of the outlet opening time on the hydrogen charging process.

The experimental and modeling results are shown in Figure 4(a) and 4(b). The initial bed temperature was approximately $102 \mathrm{~K}$. Pressure was ramped from 5 to 60 bar within 60 seconds and the inlet hydrogen temperature was maintained at $82 \mathrm{~K}$. The outlet opening times for the two cases were 9 and $71 \mathrm{~s}$, respectively. The data in Figure 4(a) show that the highest average bed temperature was $126 \mathrm{~K}$ for the case with the outlet opened at $71 \mathrm{~s}$ and $116 \mathrm{~K}$ for that at $9 \mathrm{~s}$. At the end of charging, average bed temperatures for both cases were similar.

The difference in temperature profiles can be explained as follows. When the outlet is opened earlier, the heat produced in the charging process can be removed. 
The average bed temperature rise is thus smaller. When the outlet is opened late, adsorption heat accumulates in the system and the average bed temperature rise is higher. However, the average bed temperature decreased faster for the case with the outlet opened later (at 71s) than that for the case with the outlet opened earlier (at 9s). One possible reason is that when the outlet was closed, the mixing between hot hydrogen and cold hydrogen was reduced. Hot hydrogen was pushed by the inlet hydrogen to the region close to the outlet. When the outlet was opened, hot hydrogen flowed out of the vessel quickly, which means that the heat removal for the case of $71 \mathrm{~s}$ was very efficient immediately after the outlet was opened.

In Figure 4(b), the data indicate that when the outlet is opened earlier, the storage of hydrogen in the vessel slows down, demonstrating that pressure is the main factor in deciding the amount of hydrogen stored. In the later part of the charging process, when the pressures and temperatures for the two cases are similar, the hydrogen storage for the two cases are closer. This test demonstrates that opening the outlet later increases the rate of the hydrogen storage.

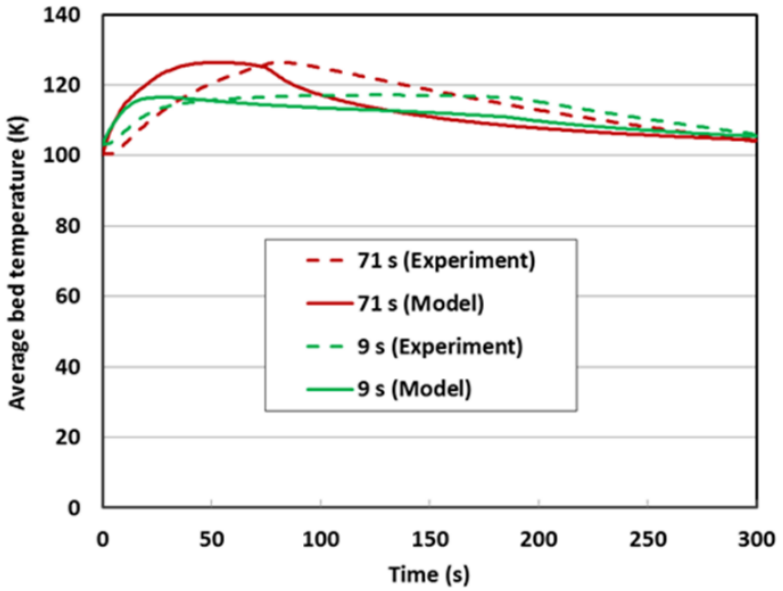

(a)

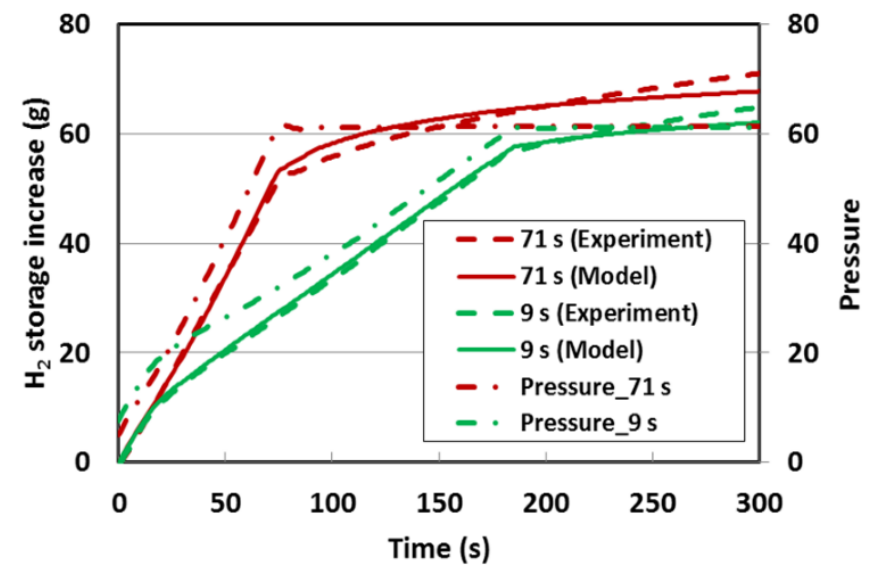

(b)

Figure 4. Effect of outlet opening time in the charging process on: (a) average bed temperature; (b) total hydrogen storage.

\subsubsection{Effect of initial bed temperature in the charging process}


With fixed pressure, the temperatures in the tank are the determining factor for the storage of hydrogen. Both the heat capacity and the mass of hydrogen are much smaller than that of the storage tank and adsorbent in the system. Due to the large thermal mass of the tank and adsorbent, manipulating their initial temperatures can greatly affect the charging process greatly. Two initial bed temperatures, $81 \mathrm{~K}$ and 100 $\mathrm{K}$, are studied in this section. The other test conditions are as follows: outlet opening time 71 seconds, pressure ramping time 60 seconds, and hydrogen inlet temperature $82 \mathrm{~K}$. The effects of initial bed temperature on the average bed temperature profile and hydrogen storage during the charging process are shown in Figures 5(a) and 5(b), respectively. The trends in temperature change were similar between the experimental data and the model results. The data in Figure 5(a) indicate that the maximum average bed temperature increase for the case with an initial bed temperature of $81 \mathrm{~K}$ was less than $20 \mathrm{~K}$, while that for the case with an initial bed temperature of $100 \mathrm{~K}$ was higher than $26 \mathrm{~K}$. In Figure 5(b), as expected, the higher initial bed temperature resulted in lower hydrogen storage. Because the system with a higher initial bed temperature requires a larger amount of cold hydrogen to cool down the system, it is detrimental to the efficiency of charging.

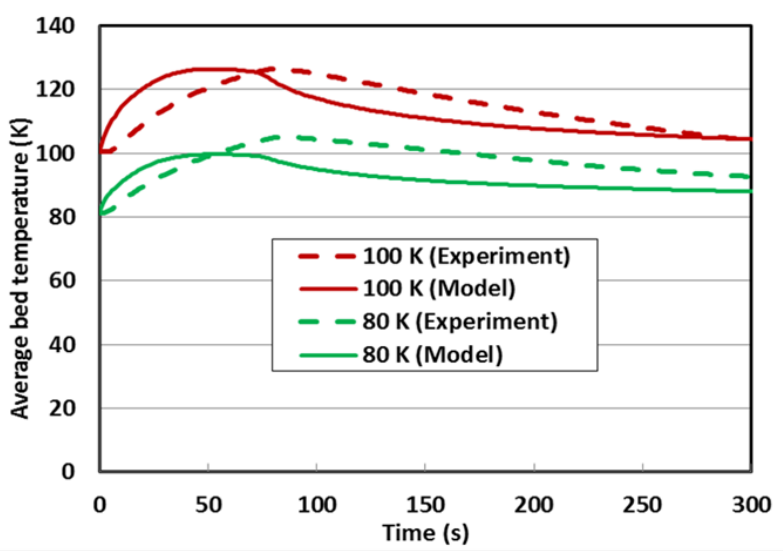

(a)

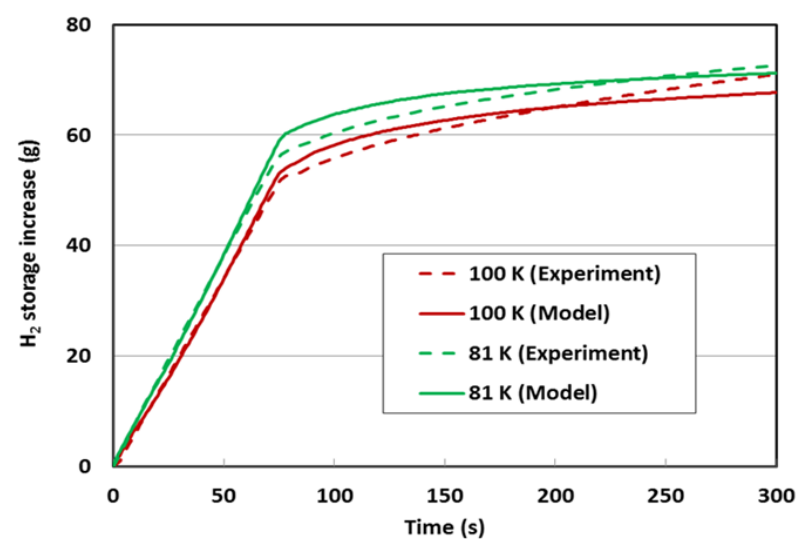

(b)

Figure 5. In charging process, the effect of initial bed temperature on: (a) average bed temperature profile; (b) on hydrogen storage.

\subsubsection{Effect of outlet mass flow rate in the charging process}


The outlet mass flow rate affects the charging process. The mass balance principle tells us that the hydrogen storage rate is the difference between the inlet and outlet mass flow rates. With a fixed inlet mass flow rate, the increase in outlet mass flow rate will decrease the rate of hydrogen storage, but will enhance the removal of adsorption heat. Therefore, it is interesting to study the effect of outlet mass flow rate on the hydrogen storage process. Two levels of outlet mass flow rate, $0.4 \mathrm{~g} / \mathrm{s}$ and $0.52 \mathrm{~g} / \mathrm{s}$, have been tested. The inlet mass flow rate was fixed at $0.65 \mathrm{~g} / \mathrm{s}$. For the case of outlet mass flow rate of $0.4 \mathrm{~g} / \mathrm{s}$, the outlet mass flow rate was increased to $0.58 \mathrm{~g} / \mathrm{s}$ at 160 s to keep the pressure within the tank no more than 60 bar.

The effect of outlet mass flow rate on the average bed temperature and hydrogen storage profile is shown in Figures 6(a) and 6(b), respectively. The data indicate that the average bed temperature for the case with the outlet mass flow rate of $0.4 \mathrm{~g} / \mathrm{s}$ was higher than that with an outlet mass flow rate of $0.52 \mathrm{~g} / \mathrm{s}$. The hydrogen storage for the case with the smaller outlet mass flow rate was higher than that with the larger outlet mass flow rate. Comparing the profiles of pressure and hydrogen storage, the connection between these two profiles was very evident. For the case with a smaller outlet mass flow rate, hydrogen storage was higher even though the average bed temperature is higher. For the case with an outlet mass flow rate of $0.52 \mathrm{~g} / \mathrm{s}$, the final pressure was less than the target pressure of 60 bar. It can be concluded that for this test, when the inlet mass flow rate was $0.62 \mathrm{~g} / \mathrm{s}$, the outlet mass flow rate of $0.52 \mathrm{~g} / \mathrm{s}$ was too high for us to ramp the pressure to 60 bar within 300 seconds. 


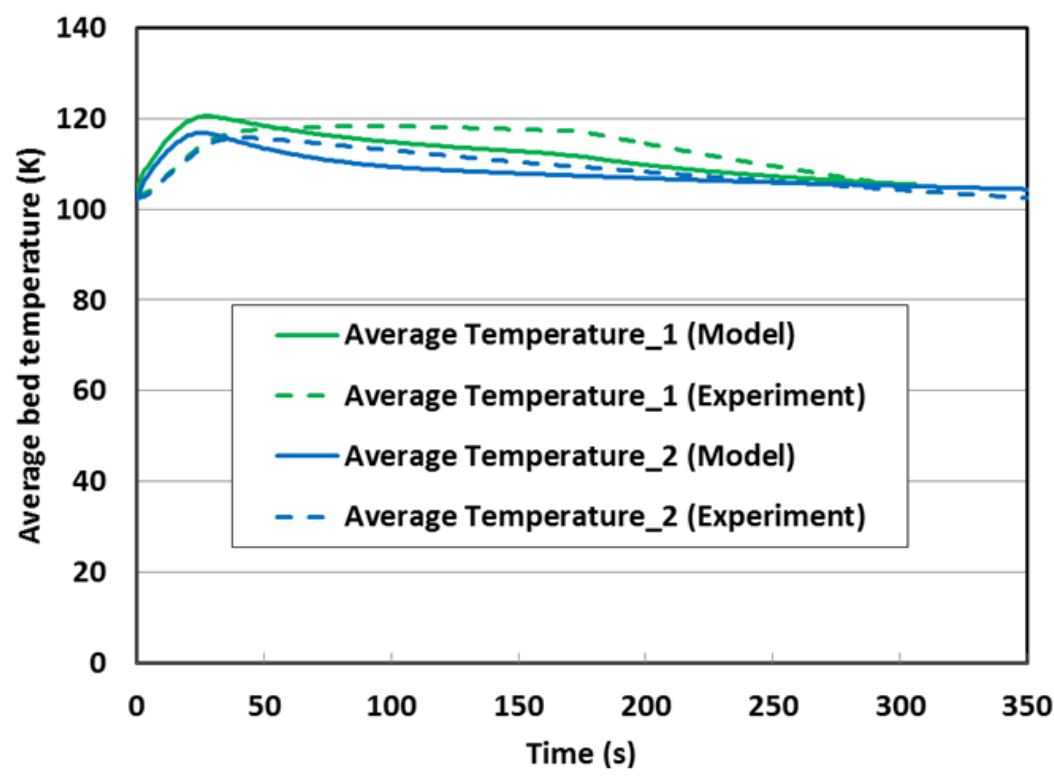

(a)

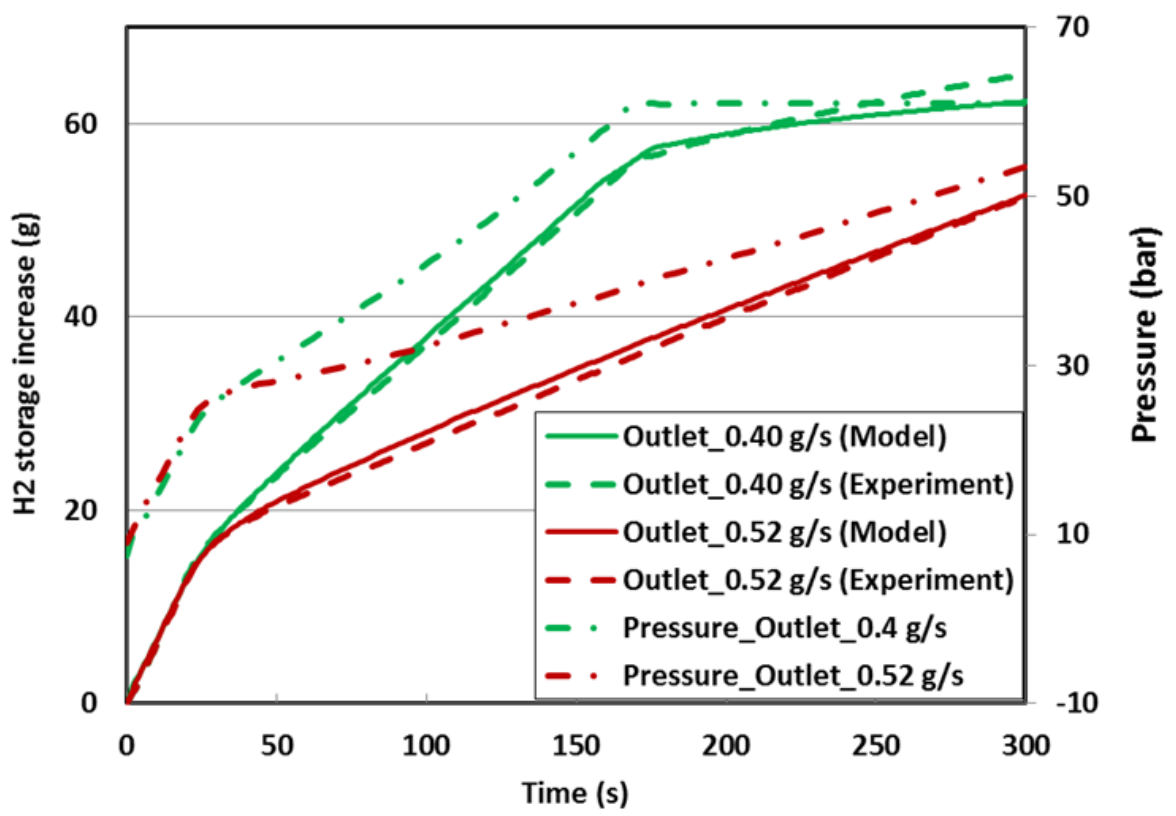

(b)

Figure 6 (a) The effect of mass flow rate on average bed temperature evolution in the charging process: Experiment_1: Outlet mass flow rate: at first $0.4 \mathrm{~g} / \mathrm{s}$; then $0.58 \mathrm{~g} / \mathrm{s}$; Experiment_2: Outlet mass flow rate: $0.52 \mathrm{~g} / \mathrm{s}$.

(b) The effect of outlet mass flow rate on hydrogen storage increase and pressure in the storage tank: Total $\mathrm{H}_{2} 1$ : Outlet mass flow rate: at first $0.4 \mathrm{~g} / \mathrm{s}$; then $0.58 \mathrm{~g} / \mathrm{s}$; Total $\mathrm{H}_{2} 2$ 2: Outlet mass flow rate: $0.52 \mathrm{~g} / \mathrm{s}$ 


\subsection{Discharging process}

The goal of the discharging process is to release hydrogen sufficiently at the desired flow rate. When pressure is high in the system, it can be used as a driving force for the discharge. However, as gaseous hydrogen and that from the early desorption phase is running out, desorption becomes difficult. Heat is needed to enhance the desorption process. In the system, heat was provided through a heating coil powered by electricity. The effect of heating power and delaying heating supply on pressure and released hydrogen have been investigated.

\subsubsection{Brief description of temperature distribution in the discharging process}

In the discharging process, the temperature distribution is of primary interest. The plots of temperature distribution predicted by the model have been published elsewhere [41]. Simulation results indicate that when heat is supplied, the temperature near the heating element rises first. When it flows to the outlet, the desorbed hydrogen heats up the bed. As discharge continues, the temperature near the closed end is lower than the initial bed temperature, due to the endothermic effect of hydrogen desorption. In the first three thousand seconds, the change in bed temperature near the closed end is minor, while that in the last one thousand seconds is significant. This is mainly because more hydrogen needs to be desorbed at the later part of the discharge process.

\subsubsection{Effect of heating power on discharging process}

Heating power is very important for a complete discharging operation. In this section, two levels of heating power were tested: 39 and $58 \mathrm{~W}$. The heater was turned on at the beginning of the discharge process and the outlet mass flow rate was set to $0.02 \mathrm{~g} / \mathrm{s}$ for the tests in this section. Temperatures and pressures in the storage tank were monitored.

\subsubsection{Temperature profiles}

Figure 7 shows the profiles of maximum, minimum, and average bed temperatures for both the experiment and model when the heating power was $39 \mathrm{~W}$. 
The maximum temperature reached was $165 \mathrm{~K}$. At the end of discharge, the average and minimum temperatures of the bed were $123 \mathrm{~K}$ and $100 \mathrm{~K}$, respectively. The experimental data and modeling results matched well for maximum and average temperatures, but there were two noticeable differences.

The first difference is that the temperature range detected by the RTDs was smaller than that predicted by the model. Regarding minimum temperatures, the predicted values were lower than the experimental measurements. This difference in temperature ranges may be attributed to two reasons. The first is in the number of values presented by these two methods. For the experiment only twenty points were measured, but for the model the temperature at every node was counted. The number of nodes in the model was far more than twenty. Statistically, it is reasonable that the temperature range predicted by the model is larger than that detected in the experiment. The second reason for the difference is that the positioning of the RTDs in the tank was restricted by the structure of the tank. RTDs are not placed in the bed near the closed end, where it was colder than the rest of the bed due to the endothermic effect of hydrogen desorption and the lack of heating. On the other hand, in order to avoid touching the heating element, the RTDs could not be placed very close to the heating element. However, the hottest points were those closest to the heating element. It is unlikely that RTDs could detect the hottest points within the bed, while the model does not have such a limitation.

The second difference between the experimental data and the model's results is that the temperature profiles curved downward near the end of the desorption simulation. This difference presents us with two questions: why does the model predicts a decreasing trend for the temperature profile? And, why do the experimental data not detect such a trend? The answer to the first question lies in the fact that the percentage of adsorbed hydrogen to the total discharged hydrogen increases in the discharge process. In the later stage of discharging, the contribution of desorbed hydrogen to the outflow of hydrogen becomes more significant because most of the compressed hydrogen has been released. For certain parts of the bed, especially those that are far from the heating element, the heat loss from hydrogen desorption was so severe that the electric heater could not fully compensate for this heat loss. Temperatures in those 
regions decreased at the end of discharging. The desorbed hydrogen, which was cold, cooled down the adsorbent as it flows out of the bed, and brought down the value of the highest temperature within the bed. The foregoing reasoning reveals that the maximum, average, and minimum temperature profiles tend to curve down at the end of discharging.

The reason that the temperature profiles for the experimental data do not curve downward may be due to the channeling effect in the bed, which causes poor heat exchange between the gas and adsorbent. As the desorbed hydrogen leaves the storage tank, the heat exchange between the gas and the solid is not as efficient as that predicted in theory due to the inhomogeneity of the adsorbent distribution. In addition, the quantity of desorbed hydrogen was small and its thermal effect on the bed temperature tended to be undetectable.

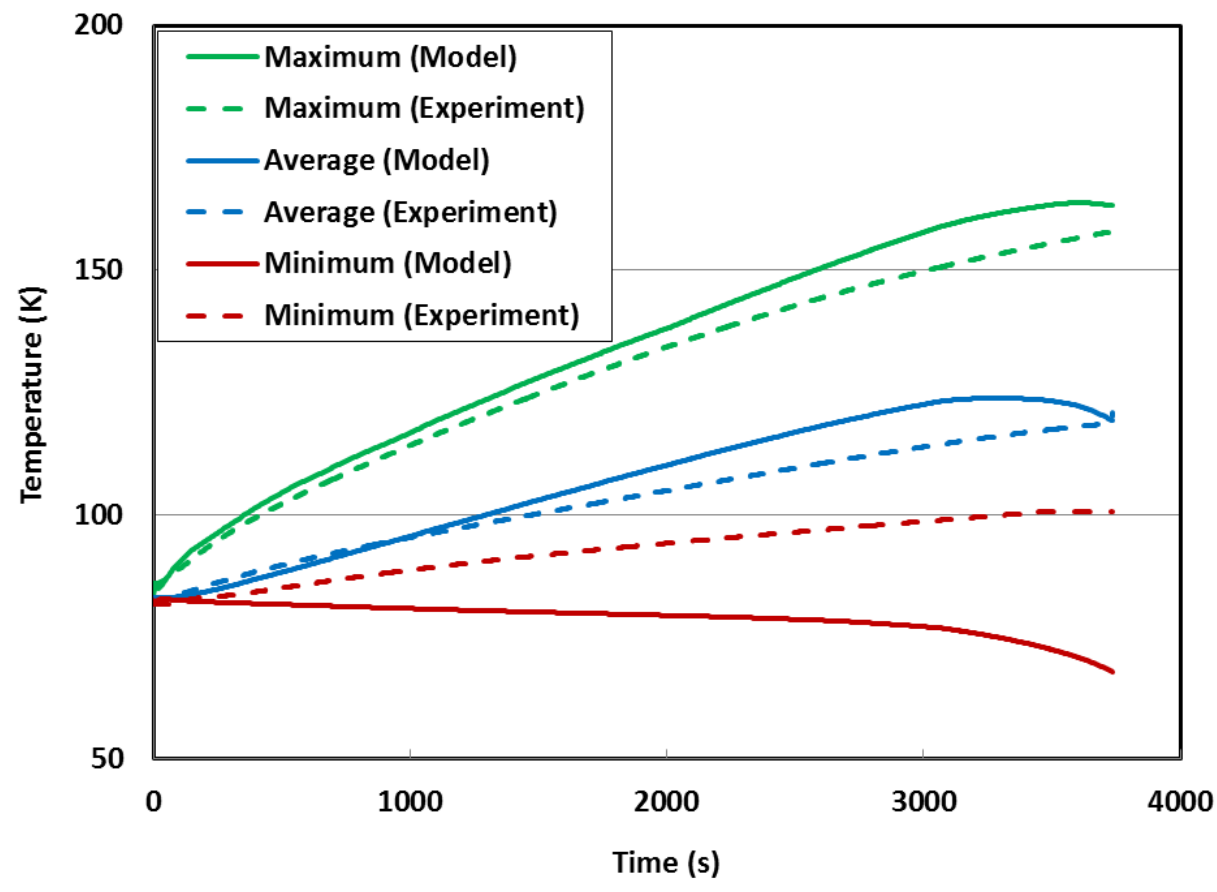

Figure 7 Temperature profiles in the discharging process with heating power as $39 \mathrm{~W}$

To meet the deliverable hydrogen targets set by DOE, the final average temperature should be around $150 \mathrm{~K}$ in the bed. Evidently, the heating power of $39 \mathrm{~W}$ is not enough for this system. A test with a heating power of $58 \mathrm{~W}$ was therefore 
conducted. The average bed temperatures for $39 \mathrm{~W}$ and $58 \mathrm{~W}$ are shown in Figure 8. When the heating power was $58 \mathrm{~W}$, the average bed temperature reached the required target. The model results and experimental data match well for the first one thousand seconds. After that, the average bed temperatures in the model are higher than those in the experiment.

The reasons for this difference are similar to those mentioned previously: the limited number of RTDs and the channeling phenomenon in the bed. As heating is turned on and desorption starts, the temperature distribution within the storage tank changes dramatically. It is difficult for the limited number of RTDs to fully capture the real temperature distribution in the bed. Because of the inhomogeneity of the adsorbent bed, the occurrence of the channeling phenomenon in a fixed bed of powder adsorbent is very likely. The heat exchange efficiency in the experiment is not as good as that in the model. Heat from the heating element is mainly transferred to the bed by convection. However, due to the channeling phenomenon, some of the hot gas would not have sufficient heat exchange with the bed before it leaves the system. Therefore, the experimental temperature values are lower than those in the simulation results.

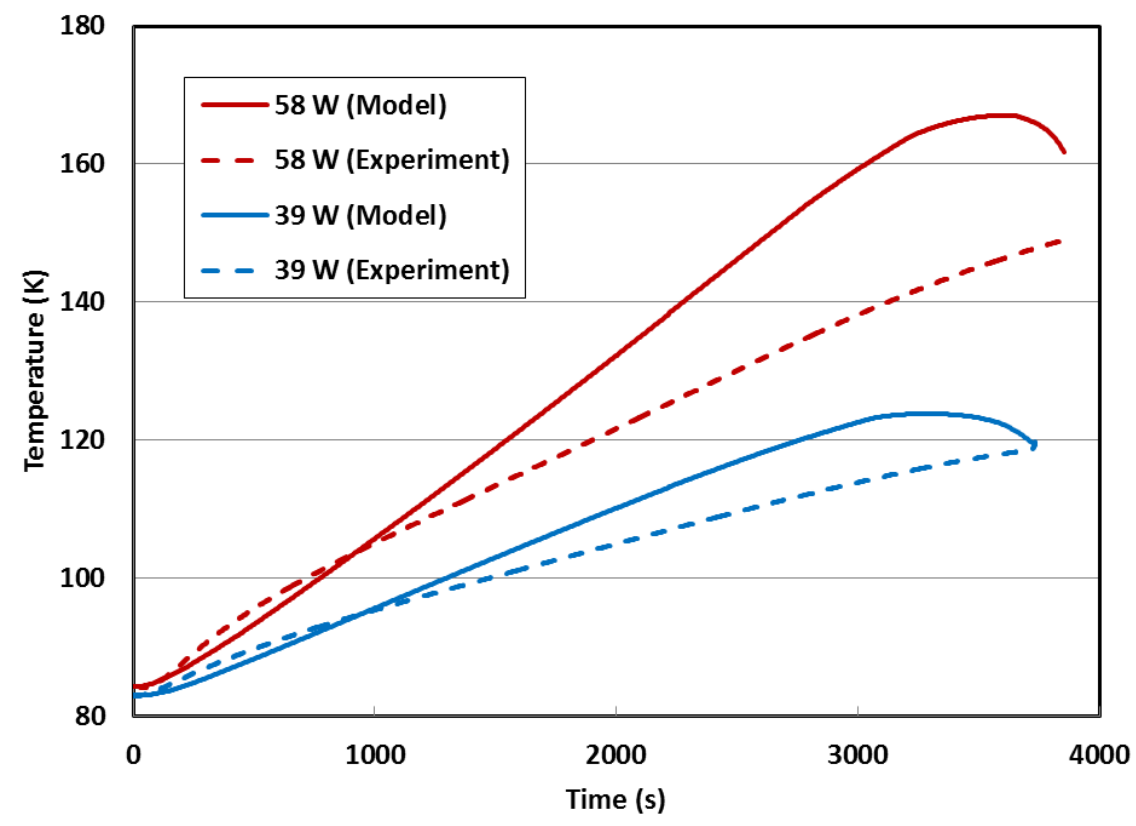

Figure 8 Comparison between average temperatures for the heating powers of 39 W and $58 \mathrm{~W}$ 


\subsubsection{Effect of heating power on pressure profiles in the discharging process}

Maintaining an adequately high pressure is very important for the smooth release of hydrogen in the discharging process. The pressure profiles as a function of heating power are shown in Figure 9. The data indicate that with the same outlet mass flow rates, the pressure in the storage tank for the $58 \mathrm{~W}$ case was higher at corresponding times, as expected.

The predicted pressure matches well with the experimental data, except for a couple of differences. First, in the beginning of discharge, there was a pressure increase detected in the experiment, but not predicted by the model. Second, in the later stage of discharge, the pressures predicted by the model were higher than those obtained in the tests.

Those two differences can be explained by the inhomogeneity of the adsorbent powder distribution in the bed. For a block where the porosity is high, the gas-solid intersurface tends to be small. In such a spacious block, the convection of gas is intense, but the efficiency of heat exchange between gas and solid is low. For a block where porosity is low, the convection of gas is weak and the heat exchange between the gas and solid is inefficient, too. In the beginning of discharge, the pressure in the real system within the storage tank builds up due to the high intensity of convection in certain regions. The adsorbent in the experiment does not take up enough heat. Supplied energy in the experiment tends to heat up gases more than that in the model. Therefore, the pressure in the experiment is higher than that in the model. In the later stage of the discharge, the heated hydrogen is more likely to flow out of the system before having sufficient heat exchange with the adsorbent due to the effect of channeling. As more energy than expected has been lost due to the effect of channeling, the average temperature in the storage tank is lower than that predicted by the model. Therefore, in the later stage of discharge, the pressure in the experiment is lower than that in the model. 


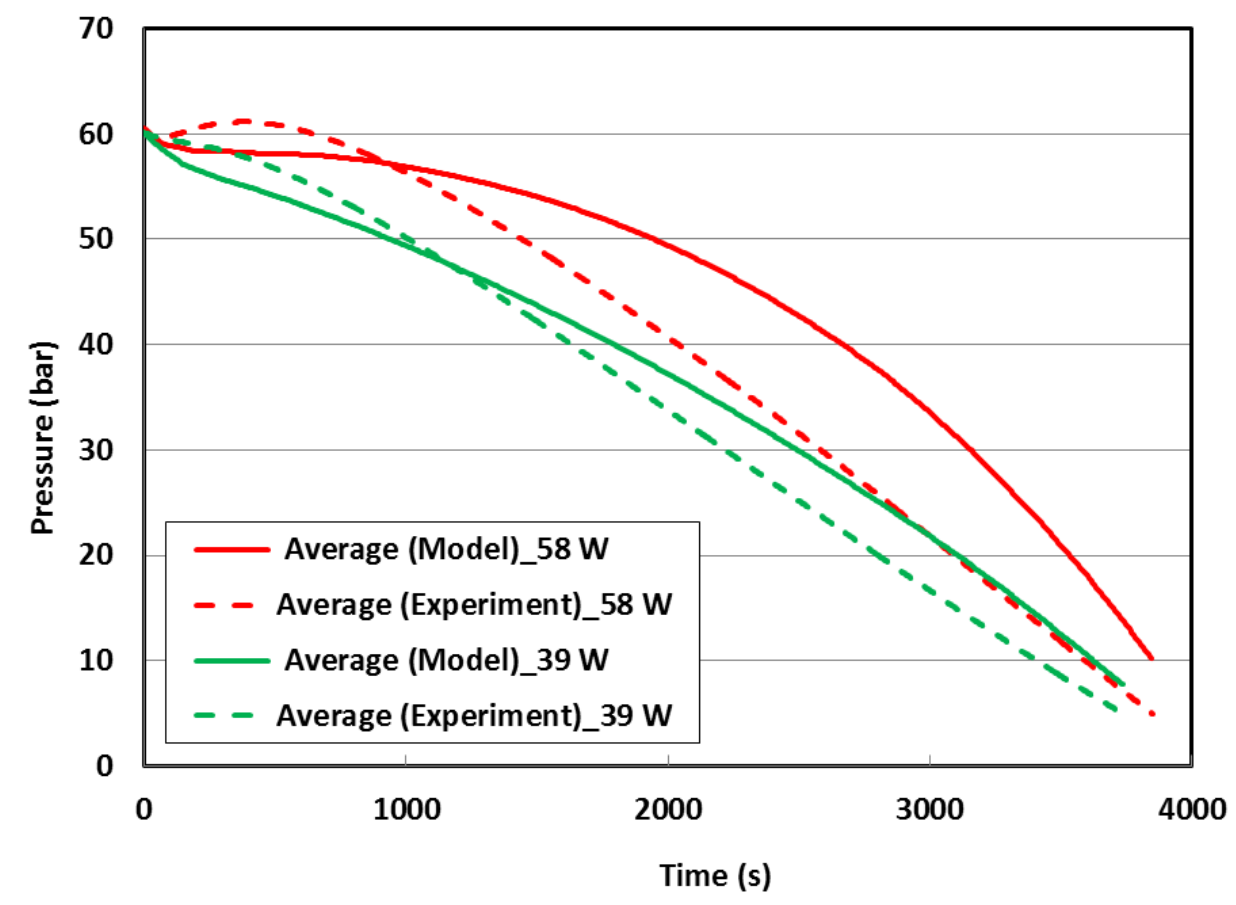

Figure 9 Comparison of average pressure in the storage tank between model and experiment for the discharging process

\subsubsection{Effect of heating power on hydrogen extraction in the discharging process}

The relationship between heating power and hydrogen storage is meaningful for the discharging operation. As discussed above, the two major parameters, $n_{\text {total }}$ and $n_{a}$, are both functions of pressure and temperature, and therefore, can be affected by heating power. The effects of heating power on hydrogen extraction are shown in Figure 10 , where the experimental data and model results are compared. The figure shows that as the heating power increases the final value of $n_{\text {total }}$ decreases. There are no experimental values of $n_{a}$, the amount of hydrogen adsorbed. The model predictions indicate that $n_{a}$ decreases with heating power. The experimental values for $n_{\text {total }}$ are calculated based on the assumption that at the beginning of the discharge, $n_{\text {total }}$ is the same for the experiment and model.

To overcome the effect of inhomogeneous temperature distribution at the end of discharge, the temperature of the system was equilibrated with the outlet being closed 
at the end of discharge for approximately two hours. The value of revised $n_{\text {total }}$ was obtained with the DA model by applying the equilibrated temperature and pressure. This data proves that the DA model was consistent over the testing ranges. Since both of the tests showed that the revised values of $n_{\text {total }}$ were close to the values predicted by the model, it is safe to say that the predictions of the DA model over the experimental range, i.e. 4 bar, $150 \mathrm{~K}$ to $60 \mathrm{bar}, 80 \mathrm{~K}$, were accurate.

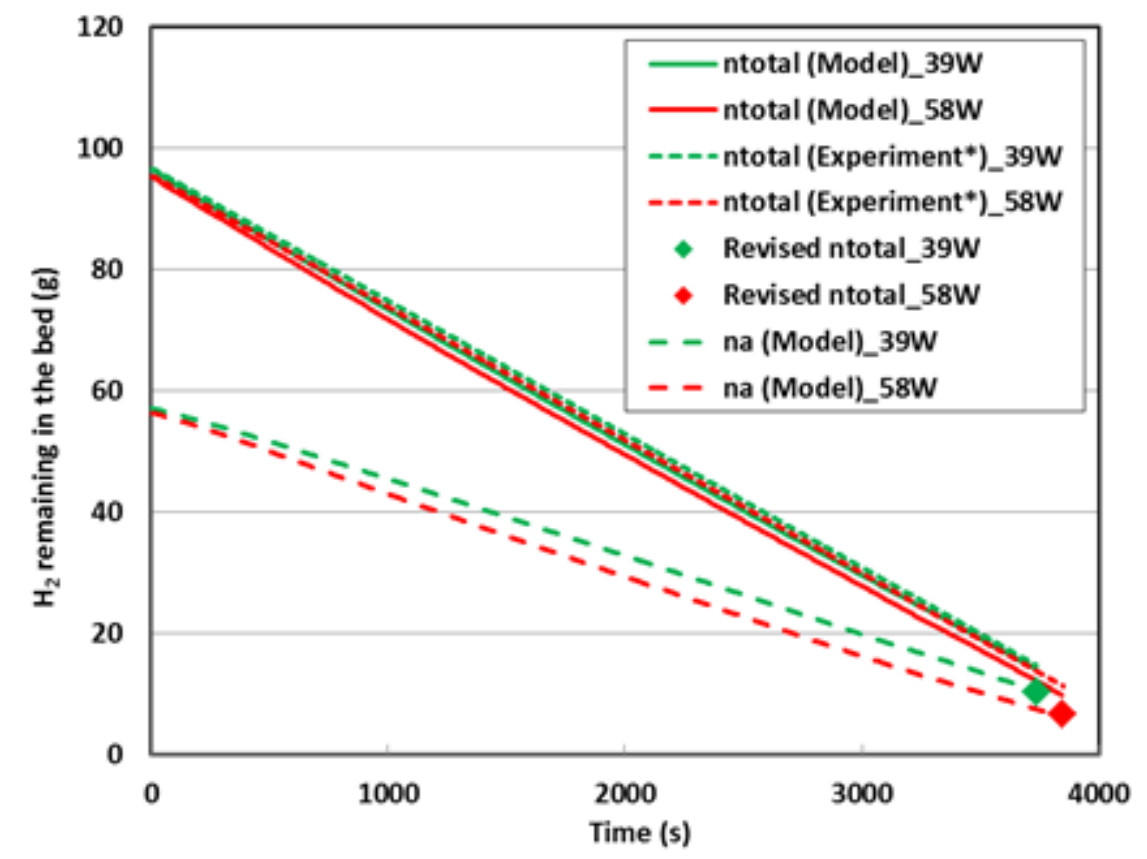

Figure 10 Effects of heating power on hydrogen extraction

\subsubsection{Effect of delaying heat supply}

With an initial pressure of 60 bar, hydrogen can be released at the desired flow rate for some period of time until the pressure is lower than a certain value. Without supplied heat, due to the endothermic effect of hydrogen desorption, the bed temperature decreases. If additional hydrogen is still needed, heat must be supplied to the system. If hydrogen is not needed for a temporary period, the lower temperature in the storage tank can extend the dormancy period. If the leftover hydrogen can be warmed up by the ambient heat during parking time, less or no heat is needed for the discharging process, and some energy can be saved. Figure 11 shows the change of 
average bed temperature in the storage tank when heat is not provided until $2160 \mathrm{~s}$, when the pressure is $10 \mathrm{bar}$. The mass discharge rate was $0.02 \mathrm{~g} / \mathrm{s}$, and heating power was $39 \mathrm{~W}$. The average bed temperature drops in the process, with the lowest value being $75 \mathrm{~K}$. The inconsistency in average bed temperatures between experiment and model at the later stage of discharge may be due to the fact that the temperatures near the closed ends were not detected in the experiment, where the temperature tends to be lower due to the endothermic effect of desorption.

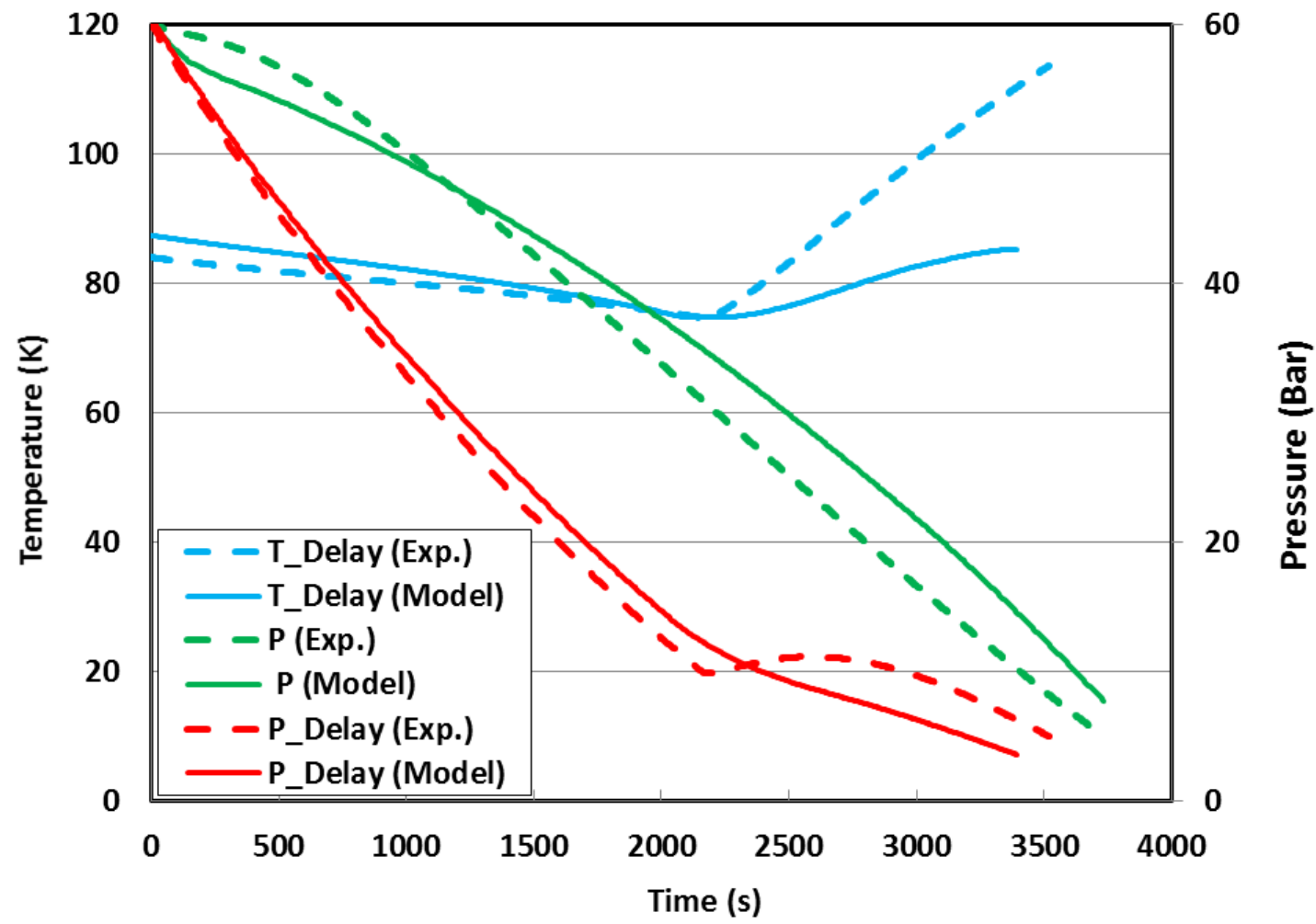

Figure 11 Change of average bed temperature and pressure with time; For delayed heating, heating started at $2160 \mathrm{~s}$

Correspondingly, the change of pressure in the storage tank for the case of delayed heating is also shown in Figure 11. The pressure change for the case of delayed heating is compared with the case where the heating starts at the beginning of the discharging process and the power for both cases is $39 \mathrm{~W}$. When there was no heating power, the pressure dropped dramatically. 


\subsection{Cyclic charging}

The storage tank can be charged in a short period of time only if the heat can quickly be removed. There are two issues with the technique of flow-through cooling. The first is the large thermal mass of the stainless steel tank and adsorbent, compared to that of hydrogen gas. To bring down the temperature of the system from $150 \mathrm{~K}$ to 80 $\mathrm{K}$ would require an extremely large amount of hydrogen to pass through the system. Another issue is that heat exchange efficiency could suffer from channeling phenomenon in the adsorbent bed.

An alternative cooling method was adopted for charging the MOF- 5 bed with hydrogen in an attempt to address the aforementioned problems. In this method, the outlet of the cryogenic test vessel was initially closed while hydrogen flowed into the vessel. After a rapid temperature increase due to the adsorption heat, the outlet was opened to release the heated gas and depressurize the vessel. The gas was discharged as fast as possible, within the instrument's safety limitations. After a pressure of 5 bar was attained, along with a corresponding drop in temperature, the outlet was then closed and a new charge/discharge cycle was initiated. Figure 12 shows the results of this experiment for a series of 5 charge/discharge cycles. The initial bed temperature was $115 \mathrm{~K}$. The minimum temperature reached was $73 \mathrm{~K}$, well below the inlet hydrogen temperature of $80 \mathrm{~K}$. This shows that the cycling method can cool certain regions of the bed to a temperature lower than that of the inlet hydrogen, making it possible to store more hydrogen. This is a definite improvement over the flowthrough cooling method, which could not achieve these low temperatures.

The advantage of cyclic cooling over flow-through cooling is that it eliminates the drawback of channeling in the flow-through cooling operation. It is a shift from continuous operation to a batch operation. The former one usually suffers from the effect of channeling, while the latter is an ideal operation which has high efficiency. In the cyclic cooling operation, there are two sub-processes: charging and discharging. In the charging period, cold hydrogen is added into the tank and mixed well within the system. In the discharging process, desorption can bring out the heat in every corner of the tank. 


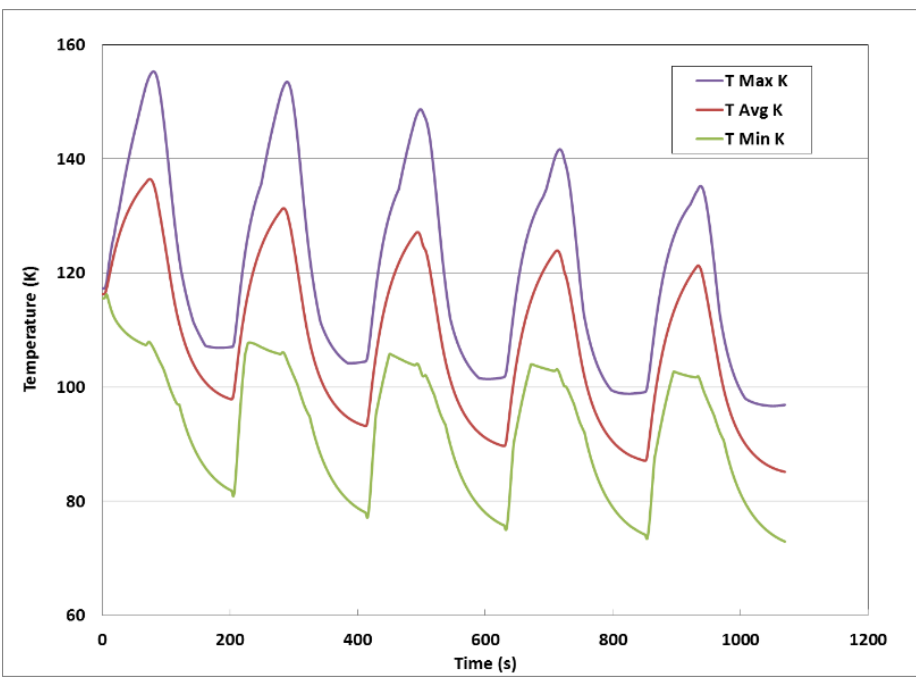

Figure 12 Rapid cooling for the charging process with initial bed temperature of $115 \mathrm{~K}$

\section{Conclusions}

The applicability of the flow-through cooling technique to remove the adsorption heat produced in the charging process has been tested and simulated. Several factors, regarding their effects on the profiles of temperature distribution, hydrogen storage and pressure evolution, have been studied. The experimental data and simulation results were compared and related. It was found that the flow-through cooling technique could remove the adsorption heat in the charging process, but some issues, such as the channeling phenomenon in the adsorbent bed and large thermal mass of the system, need to be addressed.

For the charging process, when the outlet is opened later, pressure buildup within the storage tank is faster and so is the increase of hydrogen stored. The effect of outlet mass flow rate on the charging process is similar to the effect of delaying the outlet opening time: pressure helps the buildup of hydrogen storage. When the outlet mass flow rate is too large, the buildup of hydrogen storage will be slow.

For the discharging process, in order to maintain the required hydrogen discharge rate, an adequate heating power is needed. When the pressure in the storage tank is high, hydrogen can be released from the system for a certain period of time without providing a source of heat. Experimental data and model results indicate that the DA model is adequate for the test ranges. 
Cyclic charging takes advantage of the fact that hydrogen desorption requires energy, and it can reduce the temperature in every corner of the tank when it is desorbed. Compared to the flow-through technique, the cyclic charging method could eliminate the drawbacks caused by the channeling phenomenon. The experimental data in the cyclic charging section has shown that this technique is an improvement over the flow-through cooling technique.

\section{Acknowledgements}

The authors gratefully acknowledge Sudarshan Kumar for his work on the design and build of the cryoadsorption vessel. We thank members of the DOE Hydrogen Storage Engineering Center of Excellence for fruitful discussions. We also acknowledge outstanding support from Ned Stetson, Robert Bowman, and Jesse Adams of DOE. This paper was prepared as an account of work supported by the United States Department of Energy under Contracts No. DE-FC36-09G019006 (UTRC), DE-AC0908SR22470 (SRNL), DE-FC36-09G019003 (GM), and DE-AC06-76RLO-1830 (PNNL).

\section{Disclaimer}

This work was prepared under an agreement with and funded by the U.S. Government. Neither the United States Government nor any agency thereof, nor any of their employees, makes any warranty, express or implied, or assumes any legal liability or responsibility for the accuracy, completeness, or usefulness of any information, apparatus, product, or process disclosed, or represents that its use would not infringe privately owned rights. Reference herein to any specific commercial product, process, or service by trade name, trademark, manufacturer, or otherwise, does not necessarily constitute or imply its endorsement, recommendation, or favoring by the United States Government or any agency thereof. The views and opinions of authors expressed herein do not necessarily state or reflect those of the United States Government or any agency thereof.

\section{Nomenclature}

Molar concentration of HYDROGEN, $\mathrm{mol} / \mathrm{m}^{3}$ 


\begin{tabular}{|c|c|}
\hline$C_{p}$ & Specific heat capacity of fluid at constant pressure, $\mathrm{J} /(\mathrm{kg} \cdot \mathrm{K})$ \\
\hline $\mathrm{C}_{\mathrm{pm}}$ & Heat capacity of the wall or heating elements, $\mathrm{J} /(\mathrm{kg} \cdot \mathrm{K})$ \\
\hline$C_{p, p}$ & Specific heat capacity of solid, $\mathrm{J} /(\mathrm{kg} \cdot \mathrm{K})$ \\
\hline$D_{p}$ & Effective mean pore diameter, $m$ \\
\hline Ea & Characteristic free energy of adsorption, $\mathrm{J} / \mathrm{mol}$ \\
\hline k & Heat conductivity of fluid, $\mathrm{W} /(\mathrm{m} \cdot \mathrm{K})$ \\
\hline$k_{\text {eq }}$ & Equivalent heat conductivity of the solid-fluid system, $\mathrm{W} /(\mathrm{m} \cdot \mathrm{K})$ \\
\hline $\mathrm{k}_{\mathrm{p}}$ & Heat conductivity of the solid, $\mathrm{W} /(\mathrm{m} \cdot \mathrm{K})$ \\
\hline$k_{w}$ & Heat conductivity of the wall or heating elements, $\mathrm{W} /(\mathrm{m} \cdot \mathrm{K})$ \\
\hline MHYDROGEN & Molecular weight of hydrogen, $0.002016 \mathrm{~kg} / \mathrm{mol}$ \\
\hline $\mathrm{n}_{\mathrm{a}}$ & Absolute adsorption per mass of adsorbent, mol $/ \mathrm{kg} \_a d s$ \\
\hline $\mathrm{n}_{\max }$ & $\begin{array}{l}\text { Limiting adsorption per mass of adsorbent, associated with the maximum } \\
\text { hydrogen loading of the entire adsorption volume, mol } / \mathrm{kg}_{\text {ads }}\end{array}$ \\
\hline$n_{\text {total }}$ & Total hydrogen storage per mass of adsorbent, mol $/ \mathrm{kg} \_a d s$ \\
\hline$P$ & Pressure, $\mathrm{Pa}$ \\
\hline$P_{D A}$ & Pseudo-pressure for Dubinin-Astakhov model, $\mathrm{Pa}$ \\
\hline Q & Heat source, $\mathrm{W} / \mathrm{m}^{3}$ \\
\hline $\mathrm{R}$ & Gas constant, $8.314 \mathrm{~J} /(\mathrm{mol} \cdot \mathrm{K})$ \\
\hline $\mathrm{S}_{0}$ & Mass source of hydrogen per volume, $\mathrm{kg} /\left(\mathrm{m}^{3} \cdot \mathrm{s}\right)$ \\
\hline $\mathrm{T}$ & Temperature, $\mathrm{K}$ \\
\hline$\vec{u}$ & Physical velocity vector in porous media, $\mathrm{m} / \mathrm{s}$ \\
\hline$U_{a}$ & Internal energy of the adsorbed gas per mass of adsorbent, J/kg_ads \\
\hline $\mathrm{U}_{\mathrm{c}}$ & Internal energy of the condensed phase per mass of adsorbent, J/kg_ads \\
\hline$u_{g}^{0}$ & $\begin{array}{l}\text { Specific internal energy of the perfect gas at } 1 \mathrm{~atm} \text { and temperature } \mathrm{T} \text {, } \\
\mathrm{J} / \mathrm{mol}\end{array}$ \\
\hline $\mathrm{u}_{\mathrm{s}}$ & Specific internal energy of the solid adsorbent, J/kg_ads \\
\hline V & Volume, $\mathrm{m}^{3}$ \\
\hline$\vec{v}$ & Superficial velocity vector, $\mathrm{m} / \mathrm{s}$ \\
\hline$V_{a}$ & Adsorbed volume per mass of adsorbent, $\mathrm{m}^{3} / \mathrm{kg} \_$ads \\
\hline$V_{v}$ & Void volume per mass of adsorbent, $\mathrm{m}^{3} / \mathrm{kg} \_$ads \\
\hline
\end{tabular}


Greek

a Enthalpic contribution to the characteristic free energy of adsorption, Ea, $\mathrm{J} / \mathrm{mol}$

$a_{b} \quad$ Inverse permeability, $\mathrm{m}^{-2}$

$\beta \quad$ Entropic contribution to the characteristic free energy of adsorption, Ea, $\mathrm{J} /(\mathrm{mol} \cdot \mathrm{K})$

$\Theta_{p} \quad$ Volume fraction of solid material

$\Theta_{f} \quad$ Volume fraction of fluid

$\varepsilon_{b} \quad$ Effective bed porosity, volume fraction available for flow

$\Delta \mathrm{H} \quad$ Molar enthalpy of the gas, $\mathrm{J} / \mathrm{mol}$

$\Delta \mathrm{Ua} \quad$ Internal energy of the condensed phase of the gas per mass of adsorbent at temperature $T$ and pressure $P$ relative to free gas at temperature $T$ and pressure of $1 \mathrm{~atm}, \mathrm{~J} / \mathrm{kg} \_$ads

$\Delta \bar{u}_{a} \quad$ Differential energy of adsorption, $\mathrm{J} / \mathrm{mol}$

k Bed permeability, $\mathrm{m}^{2}$

$\mu_{g} \quad$ Dynamic viscosity of hydrogen, $\mathrm{Pa} \cdot \mathrm{s}$

$\rho \quad$ Density of fluid, $\mathrm{kg} / \mathrm{m}^{3}$

$\rho_{b} \quad$ Bulk density of adsorbent, $\mathrm{kg} / \mathrm{m}^{3}$

$\rho_{\mathrm{g}} \quad$ Density of gaseous hydrogen, $\mathrm{kg} / \mathrm{m}^{3}$

$\rho_{m} \quad$ Density of the wall or heating elements, $\mathrm{kg} / \mathrm{m}^{3}$

$\rho_{p} \quad$ Solid density, $\mathrm{kg} / \mathrm{m}^{3}$

\section{References}

[1] http://www.hydrogen.energy.gov/storage.html

[2] http://www1.eere.energy.gov/hydrogenandfuelcells/storage/pdfs/targets_onboard _hydro_storage_explanation.pdf

[3] L. Zhou; Renew Sustain Energy Rev 2005; 9:395-408.

[4] A. Andreas; Materials Today 2003; 6:24-33.

[5] R. Paggiaro, F. Michl, P. Bénard, and W. Polifke; International Journal of Hydrogen Energy 2010; 35:638-47. 
[6] M.-A. Richard, P. Bénard, and R. Chahine; Adsorption 2009; 15:43-51.

[7] Y.P. Zhou, and L. Zhou; Science China (Ser B) 1996; 39:598-607.

[8] K.M. Thoms; Catalysis Today 2007; 120:389-98.

[9] L. Zhou, J.S. Zhang, and Y.P. Zhou; Langmuir 2001; 17:55903-7.

[10] R. Strobel, L. Jorisen, T. Schliermann, V. Trapp, W. Schutz, K. Bohmhammel; Journal of Power Sources 1999;84:221-224.

[11] M.G. Nijkamp, J.E. Raaymakers, A.J. van Dillen, and K.P. de Jong; Applied Physics A 2001; 72:619-623.

[12] N.L. Rosi, J. Eckert, M. Eddaoudi, D.T. Vodak, J. Kim, M. O’Keeffe; Science 2003;300:1127-9.

[13] S. Ma, J. Eckert, P. Forster, J. Yoon, Y. Hwang, J. Chang, C. Collier, J. Parise, and H. Zhou; Journal of the American Chemical Society 2008;130:15897-15902.

[14] A. Dailly, J.J. Vajo, and C.C. Ahn; Journal of Physical Chemistry B 2006; 110:1099-101.

[15] M. Cai, D. Kumar, S. Kumar, N. Kaisare, M. Sulic, J. Ortmann, and A. Chakraborty; DOE annual report (2012).

[16] H. Furukawa, M.A. Miller, and O.M. Yaghi; Journal of Materials Chemistry 2007; 17:3194-204.

[17] V. S. Kumar, K. Raghunathan, and S. Kumar; International Journal of Hydrogen Energy 2009; 34:5466-5475.

[18] V. S. Kumar, and K. Sudarshan; International Journal of Hydrogen Energy 2010; 35:3598-3609.

[19] A. Delahaye, A. Aoufi, A. Gicquel, and I. Pentchev; AIChE Journal 2002; 48:2061-73.

[20] J.S. Xiao, L. Tong, C.H. Deng, P. Bénard, and R. Chahine; International Journal of Hydrogen Energy 2010; 35:8106-16.

[21] M. Cai, P. Hou, J. P. Ortmann, and M. Sulic; http://www.hydrogen.energy.gov/pdfs/progress13/iv_b_6_cai_2013.pdf

[22] A. Chakraborty, and S. Kumar; Ineternational Journal of Hydrogen Energy 2013; 38:3973-3986. 
[23] J. Purewal, D. Liu, A. Sudik, M. Veenstra, J. Yang, S. Maurer, U. Muller, and D. Siegel; The Journal of Physical Chemistry C 2012;116:20199-20212.

[24] F. Michl, R. Paggiaro, W. Polifke, and W. Schuetz; Patent US 20080020250 A1.

[25] J.S. Xiao, J. Wang, D. Cossement, P. Bénard, and R. Chahine; International Journal of Hydrogen Energy 2012; 37:802-810.

[26] J.S. Xiao, L. Tong, D. Cossement, P. Bénard, and R. Chahine; International Journal of Hydrogen Energy 2012; 37:12893-12904.

[27] B. Hardy, C. Corgnale, R. Chahine, M.-A. Richard, S. Garrison, D. Tamburello, D. Cossement and D. Anton; International Journal of Hydrogen Energy 2012; 37:5691-5705.

[28] I. Gosh, S. Naskar, and S.S. Bandyopadhyap; International Journal of Hydrogen Energy 2010; 35:3598-609.

[29] M. M. Dubinin, and L. V. Radushkevich; Proc. Acad. Sci. Phys. CHem. Sect. USSR 1947; 55:331-333.

[30] M.-A Richard, P. Bénard, and R. Chahine; Adsorption 2009; 15:53-63.

[31] L. Zhan, K.X. Li, R. Zhang, Q.F. Liu, CH.X. Lu, and L. Ch. Ling; Journal of Supercritical Fluids 2004; 28:37-45.

[32] L. Zhou, Y.P. Zhou, and Y.A. Sun; International Journal Hydrogen Energy 2004; 29:475-9.

[33] Y.P. Zhou, K. Feng, Y.A. Sun, and L. Zhou; Chemical Physics Letter 2003; 380:526-9.

[34] G. Momen, G. Hermosilla, A. Michau, M. Pons, M. Firdaus, P.H. Marty; International Journal of Hydrogen Energy 2009;52:1495-503.

[35] G. Hermosilla-Lara, G. Momen, P.H. Marty, B. Le Neindre, and K. Hassouni; International Journal of Hydrogen Energy 2007;32:1542-53.

[36] COMSOL Multiphysics 4.2 user's guide.

[37] E.W. Lemmon, M.L. Huber, M.O. McLinden; NIST Standard Reference Database 23: reference fluid thermodynamic and transport properties-REFPROP, Version 8.0. Gaithersburg: National Institute of Standards and Technology, Standard Reference Data Program; 2007. 
[38] S. Ubaid, R. Zacharia, J. Xiao, R. Chahine, P. Nenard, P. Tessier; International Journal of Hydrogen Energy 2015; 40:30314-9325.

[39] M. Cai, A. Chakraborty, P. Hou, D. Kumar, J. Ortmann, M. Sulic; http://www.hydrogen.energy.gov/pdfs/review13/st009_cai_2013_o.pdf

[40] A. Al-Hajjaj, B. Zamora, A. A. Shah, E. Reguera, D. V. Bavykin, F. C. Walsh; International Journal of Hydrogen Energy 2011; 36:14464-14476.

[41] M. Cai, P. Hou, J. Ortmann, M. Sulic; http://www.hydrogen.energy.gov/pdfs/review14/st009_cai_2014_p.pdf 